\title{
Predictors of Tobacco Smoking Abstinence among Tuberculosis Patients in South Africa
}

\author{
Goedele MC Louwagie ${ }^{1}$, Olalekan A Ayo-Yusuf ${ }^{1,2}$ \\ ${ }^{1}$ School of Health Systems and Public Health, Faculty of Health Sciences, University of Pretoria, South Africa \\ ${ }^{2}$ Dean/Director's Office, School of Oral Health Sciences, Faculty of Health Sciences, University of Limpopo, \\ MEDUNSA Campus, South Africa \\ goedele.louwagie@up.ac.za
}

Lekan.Ayo-Yusuf@ul.ac.za

Corresponding author:

G M C Louwagie

Faculty of Health Sciences

School of Health Systems and Public Health

Private Bag X 323

Pretoria, 0001, Republic of South Africa

Tel: $+27(0) 12-354-1478$

Fax: $+27(0) 12-354-1750$

Goedele.louwagie@up.ac.za

Addresses of other author:

Professor OA Ayo-Yusuf

Dean/Director's Office School of Oral Health Sciences

University of Limpopo MEDUNSA campus

Box D12

0204

MEDUNSA, South Africa 


\section{ABSTRACT}

This study examines predictors of smoking cessation in tuberculosis patients with high HIV co-infection rates in a South African primary care setting. Current smokers were randomly allocated to brief motivational interviewing $(n=205)$ or receipt of a brief message $(n=204)$. Multi-level logistic regression was performed to identify predictors of sustained 3- and 6month abstinence and 7-day point prevalence abstinence (PPA) at 1 month, with the facility as a random effect. The intervention was ineffective among smokers with high nicotinedependence at 1 month, but was effective for all smokers over longer periods. Higher baseline self-efficacy predicted the 1-month 7-day PPA, but not sustained abstinence. HIVpositive participants' odds of sustained abstinence were about three times higher than those of their HIV-negative counterparts. Results support a more intensive motivational intervention and/or coping skills' training to increase self-efficacy and abstinence rates. Tobacco cessation services can be introduced in tuberculosis services where high HIV coinfection rates occur.

Key words: tuberculosis, smoking cessation, quitting, smoking abstinence, HIV

\section{INTRODUCTION}

Tobacco smoking approximately doubles the risk of tuberculosis (TB) infection, progression to TB disease and TB mortality (Bates et al., 2007; Lin et al., 2007; Slama et al., 2007). Moreover, if a patient who is ill with TB continues smoking, it may lead to worse TB treatment outcomes (Bonacci et al., 2013; Jee et al., 2009; Tachfouti et al., 2011). Smokers who are infected with both TB and HIV face a high risk of smoking-related complications of 
HIV (Crothers et al., 2005; Helleberg et al., 2013; Marshall et al., 2009; Van Zyl Smit et al., 2010).

Smoking cessation pilot studies were therefore recently undertaken in TB services in a variety of settings (Awaisu et al., 2011; El Sony et al., 2007; Nichter et al., 2010; Sereno et al., 2012). In Pakistan, a behavioural smoking cessation intervention (with or without buproprion therapy) was found to be highly effective in helping patients with suspected TB to quit smoking, compared to usual care (Siddiqi et al., 2013). Moreover, it was found that brief motivational interviewing (MI) delivered by lay health care workers approximately doubled smoking cessation in TB patients in a recent randomised controlled trial in a South African primary health care setting (Louwagie et al., 2014). However, these trials did not identify the predictors of smoking cessation, which may include socio-economic, smokingrelated and psycho-social characteristics.

In individual studies in a variety of non-TB settings, higher socio-economic status, being married, being male and being older have been identified as positive predictors of smoking cessation (Ayo-Yusuf \& Szymanski, 2010; Haug et al., 2010; Lee \& Kahende, 2007; Nollen et al., 2006). By contrast, other recent systematic reviews found no consistent evidence that marital status or gender are predictors for successfully quitting smoking (Jarvis et al., 2013; Vangeli et al., 2011). However, there is some evidence that social grade may exercise a beneficial effect (Vangeli et al., 2011).

The smoking-related characteristics that are most consistently predictive of failing to quit are several measures of nicotine dependence (Chandola et al., 2004; Ferguson et al., 2003; Harris et al., 2004; Hyland et al., 2006; Vangeli et al., 2011; West et al., 2001), including the number of cigarettes smoked per day (Cox et al., 2011; Haug et al., 2010; Vangeli et al., 2011; Velicer et al., 2007). Motivation-related factors (past quit attempts, 
confidence and motivation to quit, intention to quit and beliefs regarding the health effects of smoking) have also been identified as predictors of cessation in a variety of settings (AyoYusuf \& Szymanski, 2010; Cox et al., 2011; Ferguson et al., 2003; Haug et al., 2010; Velicer et al., 2007). In smokers living with HIV, motivation to quit was found to predict abstinence in two studies (Fuster et al., 2009; Lloyd-Richardson et al., 2009). However, the large-scale International Tobacco Control Four-Country project and a recent systematic review concluded that motivational factors predict "quit attempts" rather than actual future cessation (Borland et al., 2010; Hyland et al., 2006; Vangeli et al., 2011). Nevertheless, there is evidence that perceived self-efficacy to quit may predict abstinence (Cox et al., 2011; Haug et al., 2010; Hyland et al., 2006; Jardin \& Carpenter, 2012).

The evidence regarding the effects of social support on tobacco abstinence is inconclusive. Baseline social support was not found to be predictive of smoking cessation in a study of African-American light smokers (Nollen et al., 2006), but other studies found that social support did influence cessation rates (Chandola et al., 2004; Rice et al., 1996). Changes in social support as a result of the intervention did not mediate the effect of intervention on cessation in two studies (Andrews et al. 2007; Vidrine, Arduino \& Gritz, 2006), but was an independent predictor of smoking cessation in one of them (Andrews et al., 2007).

This study, which is based on secondary analysis of data from a recent South African smoking cessation trial in TB patients (Louwagie et al., 2014), aimed to identify independent predictors of smoking cessation after adjusting for the intervention effect. Identifying predictors of cessation may help to tailor interventions for different target groups in future. Moreover, smoking cessation predictors have been studied only to a limited extent in developing countries and in HIV-positive populations, and even less is known about these 
predictors in smokers with TB. Furthermore, many smoking cessation trials exclude light smokers (Faseru et al., 2013; Nollen et al., 2006). Hence, this study sought to examine predictors of smoking cessation among smokers on treatment for TB. In particular, in this study, we hypothesised that socio-economic, demographic, motivational and smokingrelated characteristics would predict sustained smoking abstinence at the 3-month and 6month follow-ups, and 7-day point PPA at the 1-month follow-up. Furthermore, we hypothesized that having an alcohol problem, using illicit drugs and having low social support would hinder cessation. The effect of being HIV-positive on successful quitting was also investigated, because it was assumed that HIV-positive smokers may encounter more barriers to quitting than their HIV-negative counterparts (Rahmanian et al., 2011). Lastly, we also explored predictors of having made a 24-hour quit attempt by the 1-month follow-up.

\section{METHODS}

\section{Design}

This was a secondary analysis of data obtained from a randomised controlled trial of brief MI for smoking cessation in TB patients at six primary care public facilities, in an informal urban setting in the City of Tshwane Metropolitan Municipality in South Africa. Smokers who were newly diagnosed TB patients and who were seeking TB treatment were randomly assigned either to participate in a once-off brief MI session (Rollnick \& Miller, 1995) with a lay health care worker (intervention, $n=205$ ) or to receive a brief cessation message from the TB nurse (control, $n=204$ ). Follow-ups were done on study participants at 1, 3 and 6 months. Allocation was concealed. Details of the study setting, recruitment, intervention, 
baseline and follow-up measurements have been described in detail elsewhere (Louwagie et al., 2014).

\section{Participants}

Of the 2411 participants screened for eligibility, 421 were identified as current smokers and 409 consented to randomisation. Eligibility criteria included being 18 years or older, being on TB treatment for less than one month, not being too ill to participate in the study, and being able to understand one of the two languages in which the questionnaire was administered (English and the most commonly used local language).

\section{Predictor variables}

Socio-economic and demographic measures included a respondent's sex, age, marital status, education and household income.

Social support was measured by means of the Rand Medical Outcomes Survey Social Support (MOS-SS) questionnaire, a reliable, validated measure with four categories of functional social support (emotional/informational, tangible, affectionate and positive social interaction) (Sherbourne \& Stewart, 1991). The 19 items are rated on a 5-point Likert-type scale with responses ranging from "none of the time" to "all of the time".

The CAGE (Cut-down, Annoyed, Guilt, Eye-opener) questionnaire, a validated brief screening tool (Dhalla \& Kopec, 2007), was used to identify respondents with a possible alcohol problem. Illicit drug use was measured by enquiring about the use of a range of commonly used illicit substances: marijuana, cocaine/crack, metamphetamine and other (not listed) substances. Answers to these questions were grouped in "yes"/"no" categories for any type of drug use.

Questions regarding tobacco use were adapted from the Global Adult Tobacco Survey questionnaire (Global Adult Tobacco Survey Collaborative Group, 2010). Participants 
were asked whether they were currently smoking "daily", "less than daily" or "not at all" (with "current" smoking being specified as any smoking in this past month). We also measured the age at which smokers started, the frequency and duration of tobacco use, participants' quit attempt history, confidence and motivation to quit (Rollnick et al., 1997) and stage of change (Prochaska \& DiClemente, 1983).

Self-efficacy (efficacy expectation) is "the conviction that one can successfully execute the behaviour required to produce the outcome" (Bandura, 1977). Self-efficacy was measured by means of a 9-item short-form self-efficacy scale which measures confidence to abstain from smoking in positive affect/social situations, negative affect situations and habitual craving situations (Velicer et al., 1990).

Nicotine dependence was assessed using the Heaviness of Smoking Index, a 2-item shortened validated version of the Fagerstrom Test for Nicotine Dependence, where a score higher than or equal to 4 indicates high dependence (De Leon et al., 2003).

\section{Outcome variables}

Our main outcome of interest was "self-reported 6-month sustained abstinence". We also ran separate models to determine the predictors of 3-month sustained abstinence and of a 7-day PPA at the 1-month follow-up, because some baseline predictors may have shortterm effects only. In addition, we ran a separate model for predictors of having made a 24hour quit attempt by the 1-month follow-up. A quit attempt was defined as not smoking for 24 hours or more, with the intention to quit.

Self-reports were biochemically verified with the $\mathrm{piCO}^{+}$Smokerlyzer carbon monoxide monitor (Bedfont Scientific Ltd, Maidstone, United Kingdom) in about half the respondents. The three available exhaled carbon monoxide monitors were rotated to half of 
the clinics, and changed over to the other half every second month. For the sub-group of participants who were offered carbon monoxide testing, self-reported abstinence was considered confirmed if the exhaled carbon monoxide levels were below 10 parts per million (West et al., 2005). However, for the predictor analysis, results were based on selfreports, as the sample size of biochemically verified results was too small for predictor analysis.

\section{Statistical procedures}

After double data entry and comparison, results were analysed using the Stata statistical package version 12 (Stata Corporation, 2011). Primary data analysis was by intention to treat, and participants lost to follow-up were classified as continued smokers. The 7-day PPA at 1 month, and the 3-month and 6-month sustained abstinence rates were first compared by potential predictor variables, using chi-square tests for categorical variables and the Wilcoxon rank sum or a Student's $t$-test for numerical variables, as appropriate.

For the multivariate analysis, we used mixed modelling logistic regression with the health facility as the random effect. All variables with a $p$-value $<0.25$ in the univariate analysis were entered in the initial model (Vittinghof et al., 2012), plus interaction variables (interaction between the intervention and nicotine dependence, and between the intervention and other variables). The least significant variables were removed, manually, one by one, until only variables with a $p$-value $<0.10$ remained in the model. At each step, likelihood tests were used to compare the more parsimonious model with the previous model. The intervention arm was, however, forced into all the models, even where it did not remain significant. 


\section{Ethical considerations}

The original trial was registered in the South African (DOH-27-0811-3539) and the Pan African (PACTR201311000695277) Clinical Trials Register and was approved by the Ethics Committee of the University of Pretoria (Protocol 116/2011). Funders had no influence on the data collection, analysis or reporting.

\section{RESULTS}

The characteristics of the trial participants are presented in Table 1. Nine out of 10 smokers were male, only about $15 \%$ had completed high school and nearly $85 \%$ lived in a household with total monthly earnings of ZAR 2500 or less (about 287 US dollars). Nearly four out of five were HIV-positive and about half had a possible alcohol problem (a CAGE score $\geq 2$ ). The median number of cigarettes smoked was low (8, interquartile range 5-13), but about one fifth of the participants showed signs of high nicotine dependence (Heaviness of Smoking Index $\geq 4)$. Smokers appeared highly motivated to quit and were confident that they could do so when measured on a 10-point scale, but their self-efficacy scores were somewhat lower (median 25, interquartile range 18-36).

Self-reported abstinence was $28.6 \%, 19.1 \%$, and $15.4 \%$ at the 1 -month, 3-month, and 6-month follow-ups respectively in the intention to treat analysis. As expected, selfreported abstinence rates were slightly higher in the per protocol analysis. However, they were similar for those who were offered carbon monoxide testing and for those not offered testing. The vast majority of self-reported abstainers $(91.4 \%, 86.1 \%$, and $94.6 \%$ at 1,3 and 6 months respectively) had an exhaled carbon monoxide level below 10 parts per million (see Table 2). 


\begin{tabular}{|c|c|}
\hline Characteristic & $N=409$ \\
\hline Men, $n / N(\%)$ & $368 / 409(90.0)$ \\
\hline Age $($ mean $[S D])(N=409)$ & $41.3(10.3)$ \\
\hline \multicolumn{2}{|l|}{ Education, $n / N(\%)$} \\
\hline Primary schooling or less & $151 / 404(37.4)$ \\
\hline Some high school & 194/404 (48.0) \\
\hline Completed high school or higher & $59 / 404(14.6)$ \\
\hline Married, $n / N(\%)$ & $114 / 406(28.1)$ \\
\hline \multicolumn{2}{|l|}{ Household earnings, $n / N(\%)$} \\
\hline $\operatorname{ZAR}^{a} 1-500$ & $138 / 403(34.2)$ \\
\hline ZAR 501-2500 & 201/403 (49.9) \\
\hline$Z A R>2500$ & $64 / 403$ (15.9) \\
\hline MOS-Social Support ${ }^{\text {b }}$ (range 21-95) (median[IQR]) $(N=392)$ & $76(63-86)$ \\
\hline Possible alcohol problem (CAGE $\geq 2)^{c}, n / N(\%)$ & $200 / 402(49.8)$ \\
\hline Illicit drug use, $n / N(\%)$ & $59 / 396(14.9)$ \\
\hline First episode of tuberculosis, $n / N(\%)$ & $347 / 398(87.2 \%)$ \\
\hline Pulmonary tuberculosis, $n / N$ (\%) & $372 / 403(92.3 \%)$ \\
\hline \multicolumn{2}{|l|}{ HIV-status, $n / N(\%)$} \\
\hline Negative & $55 / 409(13.5)$ \\
\hline Positive & $320 / 409(78.2)$ \\
\hline Unknown & $34 / 409(8.3)$ \\
\hline Age started smoking (median[IQR]) $(N=316)$ & $17(15-20)$ \\
\hline Years of regular smoking (median $[I Q R])(N=372)$ & 20. $2(14.3-27.4)$ \\
\hline Daily cigarette consumption ${ }^{d}$ (median[IQR]) $(N=341)$ & $8(5-13)$ \\
\hline Heaviness of smoking index $\geq 4^{\mathrm{e}}, n / N(\%)$ & $77 / 370(20.8)$ \\
\hline
\end{tabular}


${ }^{a}$ ZAR 8.7 1 US dollar at time of end of study

${ }^{\mathrm{b}}$ Medical Outcomes Survey, 19 items, unweighted score from 19-95

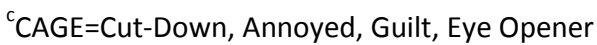

${ }^{\mathrm{d}}$ Daily smokers only

${ }^{\mathrm{e}}$ Heaviness of smoking index $\geq 4$, calculated based on sum of time to first cigarette (0: 61+min, 1:31-60 min, 2: 6-30 min, 3: $\leq 5 \mathrm{~min}$ ) and number of cigarettes smoked per day (0: 0-10 cigarettes per day [CPD], 1: 11-20 CPD, 2: 21-30 CPD, 3: 31+CPD ${ }^{\mathrm{f}}$ Cronbach alpha $=0.92$

Table 2: Self-reported and Biochemically-verified Abstinence Rates at the Three Follow-up Times

\begin{tabular}{|c|c|c|c|c|}
\hline & $\begin{array}{c}\text { Self-reported } \\
\text { abstinence for all } \\
\text { respondents (ITT } \\
\text { analysis) }\end{array}$ & $\begin{array}{l}\text { Self-reported } \\
\text { abstinence for all } \\
\text { respondents } \\
\text { followed-up } \\
\text { (PP analysis) }\end{array}$ & $\begin{array}{c}\text { Self-reported } \\
\text { abstinence for } \\
\text { respondents who } \\
\text { were offered co } \\
\text { testing }\end{array}$ & $\begin{array}{l}\text { Biochemically verified } \\
\text { abstinence }(\mathrm{CO}<10) \text { for } \\
\text { respondents with self- } \\
\text { reported abstinence }\end{array}$ \\
\hline 1-month 7-day PPA & $117 / 409(28.6)$ & $117 / 337(34.7)$ & $70 / 168(41.7)$ & $64 / 70$ (91.4) \\
\hline $\begin{array}{l}\text { 3-month sustained } \\
\text { abstinence }\end{array}$ & 78/409 (19.1) & $78 / 328(23.8)$ & $36 / 156(23.1)$ & $31 / 36(86.1)$ \\
\hline $\begin{array}{l}\text { 6-month sustained } \\
\text { abstinence }\end{array}$ & $63 / 409$ (15.4) & $63 / 313(20.1)$ & $37 / 166(22.3)$ & $35 / 37(94.6)$ \\
\hline
\end{tabular}

In the univariate analysis (see Tables 3 and 4), quit rates differed somewhat by HIV status at all three follow-up times: HIV-positive participants and those with unknown HIV 
Table 3: Univariate Analysis of Categorical Predictors of Smoking Abstinence at the 1-month, 3-month and 6-month Follow-ups

\begin{tabular}{|c|c|c|c|c|c|c|c|}
\hline & & 1 month & & 3 months & & 6 months & \\
\hline Categorical variables & $\mathbf{N}$ & $\begin{array}{c}\text { 7-day PPA } \\
\text { n (row\%) }\end{array}$ & $\begin{array}{c}\text { p- } \\
\text { value }^{a}\end{array}$ & $\begin{array}{c}\text { Sustained abstinence } \\
\mathrm{n}(\text { row\%) }\end{array}$ & p-value ${ }^{a}$ & $\begin{array}{c}\text { Sustained abstinence } \\
\mathrm{n}(\text { row\%) }\end{array}$ & p-value ${ }^{a}$ \\
\hline \multicolumn{8}{|l|}{ Alcohol problem } \\
\hline No & 202 & $52(25.7)$ & 0.242 & $34(16.8)$ & 0.412 & $29(14.4)$ & 0.552 \\
\hline Yes & 200 & $62(31.0)$ & & $40(20.0)$ & & $33(16.5)$ & \\
\hline \multicolumn{8}{|l|}{ Illicit drug use } \\
\hline No & 337 & $95(28.2)$ & 0.662 & 67 (19.9) & 0.145 & $55(16.3)$ & 0.121 \\
\hline Yes & 59 & $15(25.4)$ & & $7(11.9)$ & & $5(8.5)$ & \\
\hline \multicolumn{8}{|l|}{ HIV status } \\
\hline Negative & 55 & $9(16.4)$ & 0.084 & $4(7.3)$ & $\underline{0.040^{b}}$ & $3(5.5)$ & $0.064^{b}$ \\
\hline Positive & 320 & 99 (30.9) & & 67 (20.9) & & $54(16.9)$ & \\
\hline Unknown & 34 & $9(26.5)$ & & $7(20.6)$ & & $6(17.7)$ & \\
\hline \multicolumn{8}{|c|}{ Heaviness of smoking index $\geq 4^{c}$} \\
\hline No & 293 & $92(31.4)$ & $\underline{0.022}$ & $59(20.1)$ & 0.152 & $48(16.4)$ & 0.192 \\
\hline Yes & 77 & $14(18.2)$ & & $10(13.0)$ & & $8(10.4)$ & \\
\hline \multicolumn{8}{|c|}{ Quit attempt in past 12 months } \\
\hline No & 191 & $51(26.7)$ & 0.612 & $35(18.3)$ & 0.907 & $29(15.2)$ & 0.939 \\
\hline Yes & 207 & $60(29.0)$ & & 37 (17.9) & & $32(15.5)$ & \\
\hline \multicolumn{8}{|c|}{ Preparation stage of change } \\
\hline No & 155 & $42(27.1)$ & 0.578 & $29(18.7)$ & 0.864 & $27(17.4)$ & 0.505 \\
\hline Yes & 222 & $66(29.7)$ & & $40(18.0)$ & & $33(14.9)$ & \\
\hline
\end{tabular}

Note: PPA=point prevalence abstinence; Results for sex, education, marital status, and household income are not presented in this table (all $p$-values $>0.25$, with the exception of household income, which was significantly associated with 3-month sustained abstinence in this univariate analysis and was included in the subsequent multivariate model); Text in italics for $p$-value $<0.10$, text in underlined italics for $p$-value $<0.05$

${ }^{\mathrm{a}}$ Chi-square test

${ }^{\mathrm{b}}$ Fisher's exact test

${ }^{c}$ Heaviness of smoking index $\geq 4$. Sum of time to first cigarette (0: $61+\min , 1: 31-60 \mathrm{~min}, 2: 6-30 \mathrm{~min}, 3: \leq 5$ min) and number of cigarettes smoked per day (0: $0-10$ cigarettes per day [CPD], 1: 11-20 CPD, 2: 21-30 CPD, 3: 31+CPD ) 
Table 4 : Univariate Analysis of Numerical Predictors of Smoking Abstinence at the 1-month, 3-month and 6-month Follow-ups

\begin{tabular}{|c|c|c|c|c|c|c|c|c|c|}
\hline \multirow{3}{*}{$\begin{array}{l}\text { Numerical } \\
\text { variables }\end{array}$} & \multicolumn{3}{|c|}{1 month } & \multicolumn{3}{|c|}{3 months } & \multicolumn{3}{|c|}{6 months } \\
\hline & Still smoking & 7-day PPA & $\begin{array}{c}p- \\
\text { value }^{a}\end{array}$ & Still smoking & $\begin{array}{l}\text { Sustained } \\
\text { abstinence }\end{array}$ & $\begin{array}{c}\text { p- } \\
\text { value }^{a}\end{array}$ & Still smoking & $\begin{array}{l}\text { Sustained } \\
\text { abstinence }\end{array}$ & $\begin{array}{c}\text { p- } \\
\text { value }^{a}\end{array}$ \\
\hline & Median (IQR) & Median (IQR) & & & Median (IQR) & & Median (IQR) & Median (IQR) & \\
\hline Social support ${ }^{b}$ & $76(62-85)$ & $76(64-88)$ & 0.875 & $76(63-87)$ & $71(63-84)$ & 0.131 & $76(63-86)$ & $76.5(64-86)$ & 0.982 \\
\hline $\begin{array}{l}\text { Age started } \\
\text { smoking }\end{array}$ & $18(15-20)$ & $17(15-19)$ & 0.167 & $18(15-20)$ & $16(15-19)$ & 0.087 & $17.5(15-20)$ & $17(15-20)$ & 0.478 \\
\hline Years smoking & $20.3(14.2-27.8)$ & $20.1(15.3-27.2)$ & 0.876 & $20.1(14.2-27.5)$ & $20.5(15-27.4)$ & 0.869 & $20.2(14.1-27.4)$ & $20.3(15.1-28.2)$ & 0.709 \\
\hline $\begin{array}{l}\text { Daily number of } \\
\text { cigarettes }^{c}\end{array}$ & $8(5-15)$ & $8(4-12)$ & 0.332 & $8(5-15)$ & $7(4-10.5)$ & 0.078 & $8(5-13)$ & $7(4-13.5)$ & 0.831 \\
\hline Motivation $^{d}$ & $9(7-10)$ & $9(7-10)$ & 0.056 & $9(7-10)$ & $9(7-10)$ & 0.607 & $9(7-10)$ & $9(7-10)$ & 0.559 \\
\hline Confidence $^{d}$ & $9(6-10)$ & $9(6-10)$ & $\underline{0.034^{e}}$ & $9(6-10)$ & $9(6-10)$ & 0.389 & $9(6-10)$ & $9(6-10)$ & 0.350 \\
\hline Self-efficacy ${ }^{\mathrm{f}}$ & $24(17-33)$ & $30(21-41)$ & $\underline{0.002}$ & $25(18-34)-$ & $29(17-40)$ & 0.140 & $25(18-35)$ & $24.5(17-41)$ & 0.565 \\
\hline Belief-score ${ }^{\mathrm{g}}$ & $7(7-9)$ & $8(7-9)$ & 0.566 & $8(7-9)$ & $7(7-9)$ & 0.748 & $8(7-9)$ & $7(7-9)$ & 0.997 \\
\hline
\end{tabular}

Note: PPA=point prevalence abstinence; IQR= interquartile range; Results for age are not presented in this table, but this variable was included in the initial multivariate model if the $p$-value was $<0.25$; $\mathrm{N}$ varies between 372 and 409 , except for daily number of cigarettes, which applies only to daily smokers ( $\mathrm{N}=341)$, and age at which the participant started smoking ( $\mathrm{N}=316)$; Text in italics for $p$-value $<0.10$, text in underlined italics for $p$-value $<0.05$

${ }^{a}$ Wilcoxon rank sum test with the exception of age, where Student's t-test was used

${ }^{b} 19$ items; possible scores range from 19-95

'Daily smokers only, $\mathrm{N}=341$

d 1 item; possible scores range from 1 to 10

'Significant difference due to more respondents' having scores from 1-5 in the group that continued smoking than in the group that quit smoking, this difference is not noticeable in the IQR.

f 9 items; possible scores range from 9 to 45

$\mathrm{g}_{3}$ questions about whether smoking causes stroke, heart attack and lung cancer; possible scores range from 3 to 9 
status were more likely to quit than their HIV-negative counterparts $(30.9 \%$ and $26.5 \%$ vs. $16.4 \%$ at 1 month, $20.9 \%$ and $20.6 \%$ vs. $7.3 \%$ at 3 months, and $16.9 \%$ and $17.7 \%$ vs. $5.5 \%$ at 6 months). Self-efficacy was associated with 7-day PPA at the 1-month follow-up. Smokers with high nicotine dependence were less likely to quit than those with low nicotine dependence by the 1-month follow-up, but this effect was not sustained beyond this point in time. Ranking of motivation and confidence scores was slightly higher in participants with 7-day PPA at the 1-month follow-up, but this was not the case for longer follow-up periods.

In multivariate analysis of the predictors of 7-day PPA at the 1-month follow-up, there was significant interaction between receiving the intervention (MI) and participants' nicotine dependence status. We therefore had to stratify factors associated with smoking cessation outcomes at the 1-month follow-up by nicotine dependence status. We found that $\mathrm{MI}$ intervention was only effective for those who were categorised as having low nicotine dependence (Odds Ratio [OR] 3.01 [1.74; 5.21]). Furthermore, being HIV-positive was also only associated with abstinence among smokers with low nicotine dependence (OR 3.58, 95\% Cl 1.31; 9.78). However, baseline self-efficacy to quit was associated with 7-day PPA at the 1-month follow-up, irrespective of participants' nicotine dependence status (OR 1.03, $[95 \% \mathrm{Cl} 1.01 ; 1.06]$ and $\mathrm{OR} 1.08$ [95\% $\mathrm{Cl} 1.01 ; 1.14]$ for low-dependent and highdependent smokers respectively) (see Table 5). Confidence about being able to quit smoking at the baseline was not retained in the model: the association between confidence and abstinence found in the univariate analysis was confounded by self-efficacy to quit.

For the 3-month and 6-month multivariate models, sustained abstinence was higher among those who received $\mathrm{MI}$, and among those who were HIV-positive $(\mathrm{OR} 3.73,[95 \% \mathrm{Cl}$ $1.11 ; 12.58]$ and $\mathrm{OR} 3.17,[95 \% \mathrm{Cl} 0.93 ; 10.77]$ for the 3-month and 6-month follow-ups respectively), irrespective of their level of nicotine dependence at the baseline. Self-efficacy 
Table 5 : Independent Predictors of Smoking Abstinence at the 1-month, 3-month and 6-month Follow-ups

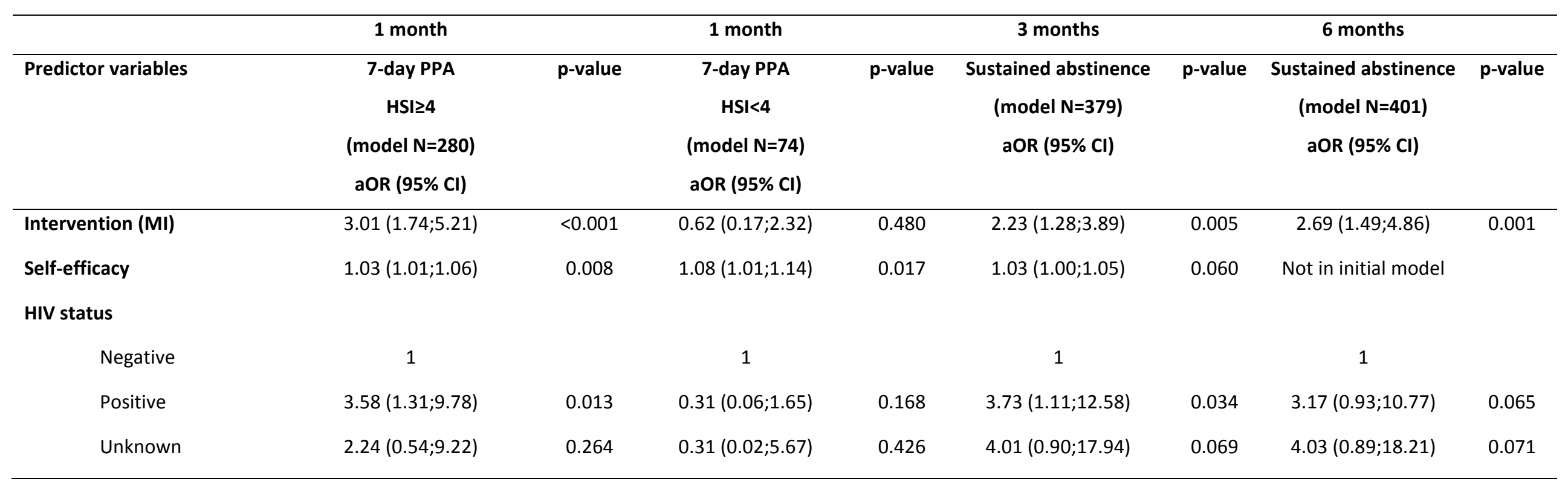

Note. aOR $(95 \% \mathrm{CI})=$ Multilevel adjusted Odds Ratio (95\% Confidence Interval) with facility as the random effect; HSI=Heaviness of smoking index $\geq 4$, calculated based on sum of time to first cigarette (0: $61+\mathrm{min}, 1: 31-60 \mathrm{~min}, 2: 6-30 \mathrm{~min}, 3: \leq 5 \mathrm{~min}$ ) and number of cigarettes smoked per day (0: 0-10 cigarettes per day [CPD], 1: 11-20 CPD, 2: 21-30 CPD, 3: 31+CPD); All variables with a $p$-value $<0.25$ in the univariate analysis were entered in the initial models and retained if there was a $p$-value $<0.10$ in the stepwise backward elimination. The intervention arm was forced in all three models. At the 1-month follow-up, the other variables entered in the initial model were: alcohol problem, HIV status, age of study participant, HSI, self-efficacy, age at which smoking was started, confidence score and interaction between intervention and HSI. The motivation score was not included because of collinearity with the confidence score. At the 3-month follow-up, these variables were: household income, illicit drug use, HIV status, HSI, social support, self-efficacy and age at which smoking was started. Number of cigarettes smoked was not included because of collinearity with the HSI. At the 6-month follow-up, these variables were: household income, illicit drug use, HIV status, HSI. 
was marginally associated with prolonged abstinence at the 3-month follow-up (see Table $5)$.

The independent predictors of having made a quit attempt by the time of the first follow-up at one month were being married ( $\mathrm{OR} 2.15,95 \% \mathrm{Cl} 1.16 ; 3.98$ ), high nicotine dependence (OR $0.49,95 \% \mathrm{Cl} 0.27 ; 0.89$ ), and smoking initiation at an older age (OR 0.93, $95 \% \mathrm{Cl} 0.89 ; 0.98)$. Stronger beliefs in the harmful effects of smoking were marginally associated with quit attempts $(p=0.092)$ (see table 6$)$.

Table 6 : Independent Predictors of Quit Attempts Undertaken at the 1-month Follow-up

Predictor variable

\section{$\mathrm{n} / \mathrm{N}$ (row \%)}

Adjusted Odds

Ratio $(95 \% \mathrm{Cl})$

\section{Intervention arm}

Control

Motivational interviewing

Marital status

\section{Not married \\ Married}

Nicotine-dependent

No
Yes

Age at which started smoking

Belief score regarding harmful effects of smoking

$125 / 204(61.3)$
$139 / 205(67.8)$

$178 / 292(61.0)$

$83 / 114(72.8)$

$200 / 293(68.3)$

$40 / 77$ (52.0)

N/A

N/A
1

$1.18(0.71 ; 1.98)$

p-value

(score from 3-9)

Note. Variables entered in the initial model were: intervention (MI), sex, marital status, nicotine dependence, MOS-social support score, age at which the participant started smoking, confidence score, belief score, age, self-efficacy. 


\section{DISCUSSION}

This study's findings show that self-efficacy and HIV-status predicted abstinence independently from the $\mathrm{MI}$ intervention. However baseline motivational factors and nicotine dependence did not predict quitting. The absence of effects from motivational factors on abstinence is consistent with findings from some (West et al., 2001; Hyland et al., 2006; Vangeli et al., 2011), but not all studies (Jardin \& Carpenter, 2012). Notwithstanding this, motivational factors may be important predictors of quit attempts (West et al., 2001; Hyland et al., 2006; Vangeli et al., 2011).

Higher self-efficacy to refrain from smoking predicted 7-day PPA at the 1-month follow-up, and marginally at the 3-month follow-up. The effect of self-efficacy on quitting is consistent with the literature (Cox et al., 2011; Haug et al., 2010; Hyland et al., 2006; Jardin \& Carpenter, 2012). However, this effect was not sustained at the 6-month follow-up. This may indicate that self-efficacy at the baseline is helpful in achieving short-term abstinence, but is not sufficient to ensure long-term cessation.

One of the methods of increasing self-efficacy could be to teach coping skills to clients with substance use disorders. It is generally accepted that better coping skills increase the likelihood of experiencing success in abstaining from substance use, and this experience of mastery may in turn enhance perceived self-efficacy (Kadden \& Litt 2011). Behavioural homework assignments are one of the techniques used that may be helpful in this context (Kazantzis \& Lampropoulos 2002). In addition to coping skills training, Kadden and Litt (2011) briefly discuss two other possible methods to enhance self-efficacy, namely $\mathrm{MI}$ and participation in a 12-step programme, such as the Alcoholics Anonymous programme. MI includes an element of "supporting self-efficacy" (Rollnick \& Miller 1995), 
but a drawback of $\mathrm{Ml}$ is that it includes few explicit instructions on how to accomplish increased self-efficacy (Kadden and Litt 2011).

In the South African context, there is a dearth of studies that evaluate the effects of coping skills training on tobacco smoking and/or substance use. In a cluster randomised controlled trial adopted in 14 TB clinics in South Africa and aimed at reducing problem drinking, no difference was found between the Information-Motivation-Behavioural Skill group and the control group (Peltzer et al., 2013). Our study participants were a vulnerable group of low socio-economic status, dealing with several co-morbidities (tobacco smoking, tuberculosis, being HIV-positive, and in some cases also illicit drug use). Any coping skills training would have to be specifically designed to deal with the complex interrelationships of these conditions. TB patients often need coping skills to adhere to prescribed medication (for TB treatment and for antiretroviral treatment if they are HIV-positive). Moreover, they may need skills to abstain from smoking and illicit drug use and to deal with stigma and practise safe sex. An alternative to coping skills training would be to provide a more intensive $\mathrm{MI}$ intervention, in particular, follow-up sessions aimed at increasing motivation and/or self-efficacy, depending on the client's stage of change. Furthermore, separate counselling sessions may be needed for each individual health-related problem.

Nicotine dependence is a well-established risk factor for failing to quit (Chandola et al., 2004; Ferguson et al., 2003; Harris et al., 2004; Hyland et al., 2006; Vangeli et al., 2011). Somewhat in contrast to this, we did not find that high nicotine dependence was a predictor of sustained smoking abstinence in our study. This cannot be attributed to selective attrition of nicotine-dependent smokers, as loss to follow-up was similar for smokers with high and smokers with low nicotine dependence. There was, however, evidence that high nicotine dependence modified the effect of the $\mathrm{MI}$ intervention, whereby $\mathrm{MI}$ was only effective for 
smokers who were not nicotine-dependent at the 1-month follow-up. The differential effect of $\mathrm{MI}$ on smoking cessation in nicotine-dependent smokers in our study may mean that this group would derive some benefit from pharmacotherapy in addition to behavioural counselling. It should, however, be noted that only one in five smokers (21\%) could be categorised as being nicotine-dependent. Behavioural interventions would therefore be an effective intervention for four-fifths of the smokers in the studied population. It is also important to take into account that the majority of our participants were light smokers. The low number of cigarettes smoked reported here is in keeping with results from general population surveys in South Africa (Ayo-Yusuf \& Agaku, 2014; Peer et al., 2009). Pharmacotherapy may in fact not confer any additional beneficial effect over and above the behavioural intervention for such smokers (Ahluwalia et al., 2006) or may only have an effect on short-term abstinence (Faseru et al., 2013).

Married participants had higher odds of making a quit attempt than their counterparts. Nicotine-dependent participants and those who started smoking at an older age were less likely to have succeeded in a quit attempt. The effect of nicotine dependence on quit attempts is in line with existing evidence (Hyland et al., 2006; Vangeli et al., 2011). In contrast with prior literature (Borland et al., 2010; Hyland et al., 2006; Vangeli et al., 2011), we did not find that "motivational factors" predicted quit attempts. The confidence score only predicted quit attempts in the univariate analysis. Ceiling effects (very high average confidence and motivation scores overall) may partially explain the absence of an effect. It is conceivable that the smokers in this study population of TB patients expressed high levels of motivation to quit smoking because both TB and smoking affect the lungs.

The finding that HIV-positive smokers were somewhat more likely to quit than HIVnegative smokers has, to our knowledge, not been reported elsewhere. In a study of 
American HIV-infected and at-risk women, no difference was reported between the annual cessation rates of HIV-negative and HIV-positive women. However, this cohort of women had overall lower cessation rates than the general population (Goldberg et al., 2010). Cessation rates were also low in a cessation trial in smokers living with HIV (LloydRichardson et al., 2009). Indirect evidence from a literature review suggests that HIVpositive smokers may find it harder to quit than HIV-negative smokers (Rahmanian et al., 2011). Factors that could compromise cessation in HIV-positive smokers are the complex management of HIV complications, dealing with a life-threatening disease and using tobacco to manage HIV-related pain symptoms (Rahmanian et al., 2011). Moreover, concomitant substance use, alcohol use and co-morbid psychiatric disorders, all of which occur more often in HIV-positive populations, are well-established risk factors for failed cessation (Rahmanian et al., 2011). On the other hand, HIV-positive smokers may be more motivated to quit because they may understand the immediate risks of continued smoking in the light of their serious life-threatening illness. Several studies have demonstrated that HIV-positive smokers are highly motivated to quit, or tried to quit in the past (Burkhalter et al., 2005; Shapiro et al., 2011) and smoking cessation trials in HIV-positive populations have shown favourable results (Lloyd-Richardson et al., 2009; Vidrine et al., 2006). In our study, HIVpositive participants' motivation score was indeed slightly higher than that of HIV-negative participants (median score 9 [IQR 7-10] vs. 8 [IQR 6-10], $p=0.06$ ). Another plausible explanation for higher cessation rates in HIV-positive TB patients is that, in our setting, TB patients who are also HIV-positive may have received additional smoking cessation advice from health providers when these patients attended antiretroviral treatment care.

Our study has some limitations. First, this is a secondary analysis of results from a randomised controlled trial. We may therefore not have measured all the important 
potential predictors. Second, predictors were only measured at the baseline. Mediating effects of changes in baseline predictors on outcomes could therefore not be evaluated. For example, changes in self-efficacy as a result of a smoking cessation intervention have been identified as a mediator of cessation outcomes in other studies (Andrews et al., 2007; Vidrine, Arduino \& Gritz, 2006). Third, the sample size of the study may have been too small to detect certain associations. Fourth, smoking abstinence was by self-report. However, biochemically verified exhaled CO monitoring was offered to about half of the participants which served as a bogus pipeline procedure. Fifth, nicotine dependence was categorised in only two instead of multiple categories. Lastly, our results are derived from a population of smokers who participated in a trial at the six largest TB clinics in one specific urban township of the City of Tshwane Metropolitan Municipality. Our results may therefore not be generalizable to all TB patients in this municipality and even less so to TB patients from other geographical areas in South Africa, particularly rural areas.

In conclusion, this is the first study to report on predictors of cessation in smokers with TB who also have HIV co-infection rates. Results suggest that self-efficacy plays a role in cessation success in the short term. Coping skills training and more intensive behavioural interventions (repeated and/or longer MI sessions) may help to increase self-efficacy, thus increasing the likelihood of abstinence. More intensive MI may also be helpful in increasing the proportion of long-term abstainers through its effects on increasing motivation to quit. Contrary to expectation, HIV-positive TB patients were more likely to quit than HIV-negative TB patients. In the light of the additional health risks posed by smoking in dually infected TB patients, this is a further argument for introducing smoking cessation services in TB care settings with high HIV co-infection rates, such as South Africa. 


\section{ACKNOWLEDGMENTS}

This project was supported by funding from the KNCV Tuberculosis Foundation (Grant 12.402.2/MvdW/U.10.0696/cal), Global Bridges Health Care Alliance for Tobacco Dependence Treatment and the National Research Foundation of South Africa (Grant\# 80843). The National Council against Smoking of South Africa provided the smoking cessation booklets offered to the study participants. We are grateful to the fieldworkers and supervisory staff, in particular Ms K. Kodi, for their enthusiastic and hard work. We also wish to thank the TB nurses at the facilities and the Tshwane District Health management team for their support.

\section{DECLARATION OF INTEREST}

The funders had no role in the conceptualisation of the study, data analysis or reporting of results. GL declares no conflict of interest. OA is a sub-awardee of an unrestricted Pfizer Education grant to the Mayo clinic for the Global Bridges Health Alliance project and received an honorarium as a speaker at the 2012 Congress of the South African Dental Association for a session on treatment funded by Pfizer.

\section{INFORMED CONSENT}

All procedures followed were in accordance with the ethical standards of the responsible committee on human experimentation (institutional and national) and with the Helsinki Declaration of 1975 , as revised in 2000 . Informed consent was obtained from all patients for being included in the study. 


\section{REFERENCES}

Ahluwalia, J. S., Okuyemi, K., Nollen, N., Choi, W. S., Kaur, H., Pulvers, K., et al. (2006). The effects of nicotine gum and counseling among African American light smokers: A 2 × 2 factorial design. Addiction, 101(6), 883-891.

Andrews, J. O., Felton, G., Ellen Wewers, M., Waller, J., \& Tingen, M. (2007). The effect of a multi-component smoking cessation intervention in African American women residing in public housing. Research in Nursing \& Health, 30(1), 45-60.

Awaisu, A., Nik Mohamed, M. H., Mohamad Noordin, N., Abd Aziz, N., Syed Sulaiman, S. A., Muttalif, A. R., et al. (2011). The SCIDOTS project: Evidence of benefits of an integrated tobacco cessation intervention in tuberculosis care on treatment outcomes. Substance Abuse Treatment, Prevention, and Policy, 6, 26. doi: 10.1186/1747-597X-6-26

Ayo-Yusuf, O. A., \& Agaku, I. T. (2014). Intention to switch to smokeless tobacco use among South African smokers: Results from the 2007 South African social attitudes survey. PloS One, 9(4), e95553.

Ayo-Yusuf, O. A., \& Szymanski, B. (2010). Factors associated with smoking cessation in South Africa. South African Medical Journal, 100(3), 175-179.

Bandura, A. (1977). Self-efficacy: Toward a unifying theory of behavioral change. Psychological Review, 84(2), 191-215.

Bates, M. N., Khalakdina, A., Pai, M., Chang, L., Lessa, F., \& Smith, K. R. (2007). Risk of tuberculosis from exposure to tobacco smoke: A systematic review and meta-analysis. Archives of Internal Medicine, 167(4), 335-342.

Bonacci, R. A., Cruz-Hervert, L. P., Garcia-Garcia, L., Reynales-Shigematsu, L. M., Ferreyra-Reyes, L., Bobadilla-Del-Valle, M., et al. (2013). Impact of cigarette smoking on rates and clinical prognosis of pulmonary tuberculosis in Southern Mexico. Journal of Infection, 66(4), 303-312.

Borland, R., Yong, H. H., Balmford, J., Cooper, J., Cummings, K. M., O'Connor, R. J., et al. (2010). Motivational factors predict quit attempts but not maintenance of smoking cessation: Findings from the International Tobacco Control Four Country project. Nicotine \& Tobacco Research, 12 Suppl, S4-11.

Burkhalter, J. E., Springer, C. M., Chhabra, R., Ostroff, J. S., \& Rapkin, B. D. (2005). Tobacco use and readiness to quit smoking in low-income HIV-infected persons. Nicotine \& Tobacco Research, 7(4), 511-522.

Chandola, T., Head, J., \& Bartley, M. (2004). Socio-demographic predictors of quitting smoking: How important are household factors? Addiction, 99(6), 770-777.

Cox, L. S., Wick, J. A., Nazir, N., Cupertino, A. P., Mussulman, L. M., Ahluwalia, J. S., et al. (2011). Predictors of early versus late smoking abstinence within a 24-month disease management program. Nicotine \& Tobacco Research, 13(3), 215220. 
Crothers, K., Griffith, T. A., McGinnis, K. A., Rodriguez-Barradas, M. C., Leaf, D. A., Weissman, S., et al. (2005). The impact of cigarette smoking on mortality, quality of life, and comorbid illness among HIV-positive veterans. Journal of General Internal Medicine, 20(12), 1142-1145.

De Leon, J., Diaz, F. J., Becona, E., Gurpegui, M., Jurado, D., \& Gonzalez-Pinto, A. (2003). Exploring brief measures of nicotine dependence for epidemiological surveys. Addictive Behaviors, 28(8), 1481-1486.

Dhalla, S., \& Kopec, J. A. (2007). The CAGE questionnaire for alcohol misuse: A review of reliability and validity studies. Clinical and Investigative Medicine, 30(1), 33-41.

El Sony, A., Slama, K., Salieh, M., Elhaj, H., Adam, K., Hassan, A., et al. (2007). Feasibility of brief tobacco cessation advice for tuberculosis patients: A study from Sudan. International Journal of Tuberculosis and Lung Disease, 11(2), 150-155.

Faseru, B., Nollen, N. L., Mayo, M. S., Krebill, R., Choi, W. S., Benowitz, N. L., et al. (2013). Predictors of cessation in African American light smokers enrolled in a bupropion clinical trial. Addictive Behaviors, 38(3), 1796-1803.

Ferguson, J. A., Patten, C. A., Schroeder, D. R., Offord, K. P., Eberman, K. M., \& Hurt, R. D. (2003). Predictors of 6-month tobacco abstinence among 1224 cigarette smokers treated for nicotine dependence. Addictive Behaviors, 28(7), $1203-1218$.

Fuster, M., Estrada, V., Fernandez-Pinilla, M. C., Fuentes-Ferrer, M. E., Tellez, M. J., Vergas, J., et al. (2009). Smoking cessation in HIV patients: Rate of success and associated factors. HIV Medicine, 10(10), 614-619.

Global Adult Tobacco Survey Collaborative Group. (2010). Global adult tobacco survey (GATS): Core questionnaire with optional questions, version 2.0. Atlanta, GA: Centers for Disease Control and Prevention.

Goldberg, D., Weber, K. M., Orsi, J., Hessol, N. A., D'Souza, G., Watts, D. H., et al. (2010). Smoking cessation among women with and at risk for HIV: Are they quitting? Journal of General Internal Medicine, 25(1), 39-44.

Harris, K. J., Okuyemi, K. S., Catley, D., Mayo, M. S., Ge, B., \& Ahluwalia, J. S. (2004). Predictors of smoking cessation among African-Americans enrolled in a randomized controlled trial of bupropion. Preventive Medicine, 38(4), 498-502.

Haug, S., Meyer, C., Ulbricht, S., Schorr, G., Ruge, J., Rumpf, H. J., et al. (2010). Predictors and moderators of outcome in different brief interventions for smoking cessation in general medical practice. Patient Education and Counseling, 78(1), 57-64.

Helleberg, M., Afzal, S., Kronborg, G., Larsen, C. S., Pedersen, G., Pedersen, C., et al. (2013). Mortality attributable to smoking among HIV-1-infected individuals: A nationwide, population-based cohort study. Clinical Infectious Diseases, 56(5), 727-734. 
Hyland, A., Borland, R., Li, Q., Yong, H. H., McNeill, A., Fong, G. T., et al. (2006). Individual-level predictors of cessation behaviours among participants in the International Tobacco Control (ITC) Four Country Survey. Tobacco Control, 15 Supp/ 3, iii83-94.

Jardin, B. F., \& Carpenter, M. J. (2012). Predictors of quit attempts and abstinence among smokers not currently interested in quitting. Nicotine \& Tobacco Research, 14(10), 1197-1204.

Jarvis, M. J., Cohen, J. E., Delnevo, C. D., \& Giovino, G. A. (2013). Dispelling myths about gender differences in smoking cessation: Population data from the USA, Canada and Britain. Tobacco Control, 22(5), 356-360.

Jee, S. H., Golub, J. E., Jo, J., Park, I. S., Ohrr, H., \& Samet, J. M. (2009). Smoking and risk of tuberculosis incidence, mortality, and recurrence in South Korean men and women. American Journal of Epidemiology, 170(12), 1478-1485.

Kadden, R. M., \& Litt, M. D. (2011). The role of self-efficacy in the treatment of substance use disorders. Addictive Behaviors, 36(12), 1120-1126.

Kazantzis, N., \& Lampropoulos, G. K. (2002). Reflecting on homework in psychotherapy: What can we conclude from research and experience? Journal of Clinical Psychology, 58(5), 577-585.

Lee, C. W., \& Kahende, J. (2007). Factors associated with successful smoking cessation in the United States, 2000. American Journal of Public Health, 97(8), 1503-1509.

Lin, H. H., Ezzati, M., \& Murray, M. (2007). Tobacco smoke, indoor air pollution and tuberculosis: A systematic review and meta-analysis. PLoS Medicine, 4(1), e20.

Lloyd-Richardson, E. E., Stanton, C. A., Papandonatos, G. D., Shadel, W. G., Stein, M., Tashima, K., et al. (2009). Motivation and patch treatment for HIV+ smokers: A randomized controlled trial. Addiction, 104(11), 1891-1900.

Louwagie, G.M., Okuyemi K.S., Ayo-Yusuf O.A. (2014). Efficacy of brief motivational interviewing on smoking cessation at tuberculosis clinics in Tshwane, South Africa: A randomised controlled trial. Addiction, doi:10.1111/ad.12671.

Marshall, M. M., McCormack, M. C., \& Kirk, G. D. (2009). Effect of cigarette smoking on HIV acquisition, progression, and mortality. AIDS Education and Prevention, 21(3 Suppl), 28-39.

Nichter, M., Nichter, M., Muramoto, M., \& Project Quit Tobacco International. (2010). Project Quit Tobacco International: Laying the groundwork for tobacco cessation in low- and middle-income countries. Asia-Pacific Journal of Public Health, 22(3 Suppl), 181S-188S. 
Nollen, N. L., Mayo, M. S., Sanderson Cox, L., Okuyemi, K. S., Choi, W. S., Kaur, H., et al. (2006). Predictors of quitting among African American light smokers enrolled in a randomized, placebo-controlled trial. Journal of General Internal Medicine, 21(6), 590-595.

Peer, N., Bradshaw, D., Laubscher, R., \& Steyn, K. (2009). Trends in adult tobacco use from two South African demographic and health surveys conducted in 1998 and 2003. South African Medical Journal, 99(10), 744-749.

Peltzer, K., Naidoo, P., Louw, J., Matseke, G., Zuma, K., McHunu, G., et al. (2013). Screening and brief interventions for hazardous and harmful alcohol use among patients with active tuberculosis attending primary public care clinics in South Africa: Results from a cluster randomized controlled trial. BMC Public Health, 13, 699-2458-13-699.

Prochaska, J. O., \& DiClemente, C. C. (1983). Stages and processes of self-change of smoking: Toward an integrative model of change. Journal of Consulting \& Clinical Psychology, 51(3), 390-395.

Rahmanian, S., Wewers, M. E., Koletar, S., Reynolds, N., Ferketich, A., \& Diaz, P. (2011). Cigarette smoking in the HIVinfected population. Proceedings of the American Thoracic Society, 8(3), 313-319.

Rice, V. H., Templin, T., Fox, D. H., Jarosz, P., Mullin, M., Seiggreen, M., et al. (1996). Social context variables as predictors of smoking cessation. Tobacco Control, 5(4), 280-285.

Rollnick, S., Butler, C. C., \& Stott, N. (1997). Helping smokers make decisions: The enhancement of brief intervention for general medical practice. Patient Education and Counseling, 31(3), 191-203.

Rollnick, S., \& Miller, W.R. (1995). What is motivational interviewing? Behavioral and Cognitive Psychotherapy, 23, 325-334.

Sereno, A. B., Soares, E. C., Lapa E Silva, J. R., Napoles, A. M., Bialous, S. A., Costa E Silva, V. L., et al. (2012). Feasibility study of a smoking cessation intervention in directly observed therapy short-course tuberculosis treatment clinics in Rio de Janeiro, Brazil. Pan American Journal of Public Health, 32(6), 451-456.

Shapiro, A. E., Tshabangu, N., Golub, J. E., \& Martinson, N. A. (2011). Intention to quit smoking among human immunodeficiency virus infected adults in Johannesburg, South Africa. International Journal of Tuberculosis and Lung Disease, 15(1), 140-142.

Sherbourne, C. D., \& Stewart, A. L. (1991). The MOS social support survey. Social Science \& Medicine, 32(6), 705-714.

Siddiqi, K., Khan, A., Ahmad, M., Dogar, O., Kanaan, M., Newell, J. N., et al. (2013). Action to Stop Smoking in Suspected Tuberculosis (ASSIST) in Pakistan: A cluster randomized, controlled trial. Annals of Internal Medicine, 158(9), 667675. 
Slama, K., Chiang, C. Y., Enarson, D. A., Hassmiller, K., Fanning, A., Gupta, P., et al. (2007). Tobacco and tuberculosis: A qualitative systematic review and meta-analysis. International Journal of Tuberculosis and Lung Disease, 11(10), 1049-1061.

Stata Corporation. (2011). Stata statistical software: Release 12. College Station, TX: StatCorp.

Tachfouti, N., Nejjari, C., Benjelloun, M. C., Berraho, M., Elfakir, S., El Rhazi, K., et al. (2011). Association between smoking status, other factors and tuberculosis treatment failure in Morocco. International Journal of Tuberculosis and Lung Disease, 15(6), 838-843.

Van Zyl Smit, R. N., Pai, M., Yew, W. W., Leung, C. C., Zumla, A., Bateman, E. D., et al. (2010). Global lung health: The colliding epidemics of tuberculosis, tobacco smoking, HIV and COPD. European Respiratory Journal, 35(1), 27-33.

Vangeli, E., Stapleton, J., Smit, E. S., Borland, R., \& West, R. (2011). Predictors of attempts to stop smoking and their success in adult general population samples: A systematic review. Addiction, 106(12), 2110-2121.

Velicer, W. F., Diclemente, C. C., Rossi, J. S., \& Prochaska, J. O. (1990). Relapse situations and self-efficacy: An integrative model. Addictive Behaviors, 15(3), 271-283.

Velicer, W. F., Redding, C. A., Sun, X., \& Prochaska, J. O. (2007). Demographic variables, smoking variables, and outcome across five studies. Health Psychology, American Psychological Association, 26(3), 278-287.

Vidrine, D. J., Arduino, R. C., \& Gritz, E. R. (2006). Impact of a cell phone intervention on mediating mechanisms of smoking cessation in individuals living with HIV/AIDS. Nicotine \& Tobacco Research, 8 Suppl 1, S103-8.

Vidrine, D. J., Arduino, R. C., Lazev, A. B., \& Gritz, E. R. (2006). A randomized trial of a proactive cellular telephone intervention for smokers living with HIV/AIDS. AIDS, 20(2), 253-260.

Vittinghoff, E., Glidden D.V., Shiboski S.C., \& McCulloch C.E (2012). Chapter 10. Predictor selection. In: Regression methods in biostatistics: linear, logistic, survival, and repeated measures models. $\left(2^{\text {nd }}\right.$ edn.). Springer Link, pp. 395-429. Available online: http://link.springer.com/chapter/10.1007/978-1-4614-1353-0_10/fulltext.html. Accessed 21 October 2013.

West, R., McEwen, A., Bolling, K., \& Owen, L. (2001). Smoking cessation and smoking patterns in the general population: A 1-year follow-up. Addiction, 96(6), 891-902.

West, R., Hajek, P., Stead, L., \& Stapleton, J. (2005). Outcome criteria in smoking cessation trials: Proposal for a common standard. Addiction, 100(3), 299-303. 